Cite this: Chem. Commun., 2014 , 50,6270

Received 11th April 2014, Accepted 18th April 2014

DOI: $10.1039 / \mathrm{c} 4 \mathrm{cc} 02701 \mathrm{a}$

www.rsc.org/chemcomm

\section{Reduced graphene oxide supported piperazine in aminocatalysis $\dagger$}

\author{
Eduardo Rodrigo, ${ }^{a}$ Beatriz García Alcubilla, ${ }^{a}$ Raquel Sainz, ${ }^{b}$ J. L. García Fierro, ${ }^{c}$ \\ Rafael Ferritto ${ }^{b}$ and M. Belén Cid*a
}

Reduced graphene oxide (rGO) has been used as a support for piperazine to provide a heterogeneous bifunctional organocatalyst (rGO-NH) that is able to efficiently promote vintage organic transformations such as Knoevenagel, Michael and aldol reactions. The obtained results suggest a significant role of the support in the course of these reactions.

The interest shown in graphene and its applications has significantly increased in the last few years. ${ }^{1}$ In addition to graphene, other derivatives such as graphene oxide $(\mathrm{GO})^{2}$ have been demonstrated to be capable of promoting some organic reactions. However, the use of covalently functionalized structures based on graphene to catalyse organic reactions has been scarcely explored and the scope and variety of reactions analysed are very limited. ${ }^{3}$

Although supported catalysts have demonstrated high utility in organic synthesis, ${ }^{4}$ the surface areas of these heterogeneous materials are normally inactive. It has been proposed that graphene and its derivatives may function as a Lewis base, stabilizing cationic species $^{5}$ and therefore their electronic properties ${ }^{6}$ might offer some advantages compared with other surfaces. Interestingly, the high catalytic ability of amines, ${ }^{7}$ recognised as a highly useful tool in organic chemistry, ${ }^{8}$ mainly implies cationic intermediates such as iminium or ammonium species. As a consequence, we considered that the study of the catalytic properties of directly anchored amines on an rGO surface could be of interest, as the support could help to stabilize those positively charged intermediates accelerating some processes.

We present herein the preparation, characterization and effective use of rGO-NH as a catalyst in a variety of organic reactions, which presumably involve iminium and ammonium

\footnotetext{
${ }^{a}$ Department of Organic Chemistry, Universidad Autónoma de Madrid, Cantoblanco 28049, Madrid, Spain. E-mail: belen.cid@uam.es

${ }^{b}$ Nanoinnova Technologies SL, Parque Científico de Madrid, Calle Faraday, 7, 28049 Madrid, Spain

${ }^{c}$ Instituto de Catálisis y Petroleoquimica, CSIC, C/Marie Curie 2, Cantoblanco, 28049 Madrid, Spain

† Electronic supplementary information (ESI) available. See DOI: 10.1039/ c4cc02701a
}
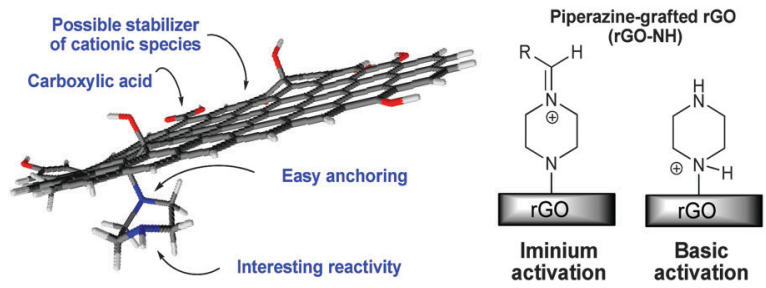

Fig. 1 Working hypothesis: piperazine-grafted reduced graphene oxide $(\mathrm{rGO}-\mathrm{NH})$ as the catalyst in organic reactions.

ions of a piperazine-grafted reduced graphene oxide material (rGO-NH) (Fig. 1). The presence of two nitrogen atoms in piperazine not only simplifies the anchoring, but also affords a bifunctional catalyst that opens different reactivity pathways like iminium and basic activation (Fig. 1).

The preparation of rGO-NH was carried out in three steps: (a) oxidation of graphite powder using a modified Hummers' $\operatorname{method}^{9}$ followed by sonication in order to get the exfoliation of the material; (b) opening of the resulting epoxides with piperazine through nucleophilic substitution ${ }^{10}$ and (c) reduction with hydrazine in basic medium ${ }^{11}$ (Scheme 1).

The introduction of piperazine into the support as well as the characterization of the material has been unequivocally

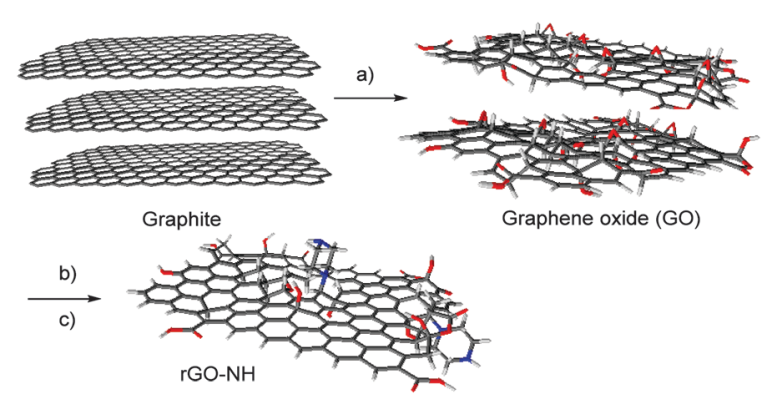

a) i. $\mathrm{NaNO}_{3}, \mathrm{H}_{2} \mathrm{SO}_{4}, \mathrm{KMnO}_{4}, \mathrm{H}_{2} \mathrm{O}_{2} / \mathrm{H}_{2} \mathrm{O}$; ii. US; b) Piperazine, $\mathrm{H}_{2} \mathrm{O} / \mathrm{EtOH}$, $100^{\circ} \mathrm{C}, 24 \mathrm{~h}$; c) $\mathrm{NH}_{2} \mathrm{NH}_{2}, \mathrm{NH}_{4} \mathrm{OH}$ (pH 10), $100^{\circ} \mathrm{C}, 1 \mathrm{~h}$

Scheme 1 Preparation of rGO-NH from graphite. 
Table 1 Knoevenagel reaction

\begin{tabular}{|c|c|c|c|c|c|c|}
\hline & $\mathrm{R}_{1 \mathrm{a}-\mathrm{c}}^{\mathrm{CN}}$ & $\mathrm{R}^{2}{ }_{\mathrm{a}-\mathrm{f}}$ & $\underset{\mathrm{EtOH}, 60^{\circ} \mathrm{C}}{\stackrel{\mathrm{rGO}-\mathrm{NH}}{\longrightarrow}}$ & $\begin{array}{l}\mathrm{R}^{2} \mathrm{H} \\
\text { 3aa-cf }\end{array}$ & 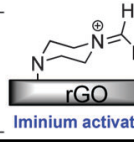 & tion \\
\hline Entry & $\mathrm{R}^{2}$ & $\mathrm{R}^{1}$ & & Product & Time (h) & Yield (\%) \\
\hline 1 & $\mathbf{1 a}\left(\mathrm{CO}_{2} \mathrm{Et}\right)$ & $2 \mathbf{a}(\mathrm{Ph})$ & & $3 \mathbf{a a}$ & 21 & 83 \\
\hline 2 & $\mathbf{1 a}\left(\mathrm{CO}_{2} \mathrm{Et}\right)$ & $2 \mathbf{b}(p-\mathrm{ON}$ & Me- $\left.\mathrm{C}_{6} \mathrm{H}_{4}-\right)^{b}$ & $3 a b$ & 24 & 78 \\
\hline 3 & $\mathbf{1 a}\left(\mathrm{CO}_{2} \mathrm{Et}\right)$ & $2 \mathrm{c}(p-\mathrm{NO}$ & $\left.{ }_{2}-\mathrm{C}_{6} \mathrm{H}_{4}-\right)$ & $3 a c$ & 7 & 80 \\
\hline 4 & $\mathbf{1 b}(\mathrm{COPh})$ & $2 \mathbf{a}(\mathrm{Ph})$ & & $3 \mathbf{b a}$ & 24 & 88 \\
\hline 5 & $\mathbf{1 b}(\mathrm{COPh})$ & $2 \mathbf{b}(p-\mathrm{ON}$ & Me- $\left.\mathrm{C}_{6} \mathrm{H}_{4}^{-}\right)$ & $3 \mathbf{b b}$ & 24 & 90 \\
\hline 6 & $\mathbf{1 b}(\mathrm{COPh})$ & $2 \mathrm{c}(p-\mathrm{NO}$ & $\left.{ }_{2}-\mathrm{C}_{6} \mathrm{H}_{4}-\right)$ & $3 b c$ & 7 & 83 \\
\hline 7 & $1 \mathrm{c}(\mathrm{CN})$ & $2 a(P h)$ & & $3 c a$ & 21 & 86 \\
\hline 8 & $1 \mathrm{c}(\mathrm{CN})$ & $2 \mathbf{b}(p-\mathrm{ON}$ & Me- $\left.\mathrm{C}_{6} \mathrm{H}_{4}-\right)$ & $3 \mathrm{cb}$ & 21 & 81 \\
\hline 9 & $1 \mathrm{c}(\mathrm{CN})$ & $2 \mathrm{c}(p-\mathrm{NO}$ & $\left.{ }_{2}-\mathrm{C}_{6} \mathrm{H}_{4}-\right)^{b}$ & $3 c c$ & 3 & 87 \\
\hline 10 & $1 \mathrm{c}(\mathrm{CN})$ & $2 d(\mathrm{CH}=$ & $=\mathrm{CH}-\mathrm{Ph})$ & $3 c d$ & 16 & 85 \\
\hline 11 & $1 \mathrm{c}(\mathrm{CN})$ & $2 \mathrm{e}(\mathrm{CH}=$ & $\left.=\mathrm{CH}-\mathrm{CH}_{3}\right)$ & $3 c e$ & 16 & 88 \\
\hline 12 & $1 \mathrm{c}(\mathrm{CN})$ & $\begin{array}{c}2 \mathrm{f}\left(\mathrm{CH}_{2}-\right. \\
\mathbf{2 g}\end{array}$ & $\left.\mathrm{CH}-\left(\mathrm{CH}_{3}\right)_{2}\right)$ & $3 \mathrm{cf}$ & 20 & 89 \\
\hline $13^{c}$ & $1 \mathrm{c}(\mathrm{CN})$ & & & & 65 & 68 \\
\hline
\end{tabular}

${ }^{a} 0.3 \mathrm{mmol}$ of aldehyde was used and $50 \mathrm{mg}$ of rGO-NH was used. ${ }^{b}$ We have observed that those reactions, although to a much smaller extent, also take place in the absence of the catalyst (see ESI for more details). ${ }^{c} 3$ equiv. of nucleophile and toluene at $80{ }^{\circ} \mathrm{C}$ was used.

demonstrated using different techniques: X-ray diffraction (XRD), field emission scanning electron microscopy (FE-SEM), energy dispersive spectroscopy (EDS) mapping, X-ray photoelectron spectroscopy (XPS), FT-IR spectroscopy, and thermogravimetric and elemental analyses. ${ }^{12}$

Once the material was characterized and we had determined that the process for obtaining it was reproducible and scalable to at least $10 \mathrm{~g}$ of rGO-NH, we checked the catalytic ability of the anchored catalyst. First we decided to exploit the advantages of the supported catalyst in the classical Knoevenagel condensation, which is typically catalysed by amines, mainly secondary ones via iminium ion activation (Table 1). We were glad to observe that the Knoevenagel reaction afforded high yields with different nucleophiles (1a-c) and a variety of aromatic aldehydes, with both electron donating and electron withdrawing groups (2a-c) (entries 1-9). Other types of aldehydes, such as $\alpha, \beta$-unsaturated (2d and $2 \mathbf{2}$ ) and aliphatic aldehydes (2f), also provided high yields (entries 10-12). Even ketones could also be employed as electrophiles, i.e. 1,4-cyclohexanedione afforded $3 \mathrm{cg}$ in a $68 \%$ yield (entry 13). Compound $\mathbf{3 c g}$ is an immediate precursor of tetracyanoquinodimethane (TCNQ), ${ }^{13}$ an electron-acceptor compound of high interest in the area of molecular electronics. ${ }^{14}$ Moreover, we have proven, in the preparation of 3cc, that the material might be recovered and used without losing efficiency after at least 3 cycles.

After verifying the efficiency of the nucleophilic secondary amine in a reaction that most likely occurs via iminium ion activation, we decided to explore the Michael addition of nitromethane to 3ca, obtained in the Knoevenagel condensation (Table 1, entry 7), because it would offer the opportunity to go a bit further and explore the synthetic possibilities of this bifunctional heterogeneous catalyst using both abilities (presumably iminium and basic activation) in a one-pot process

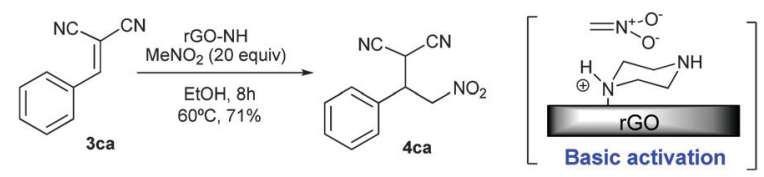

Scheme 2 Michael addition via base activation.

Table 2 Knoevenagel-Michael one-pot process ${ }^{a}$

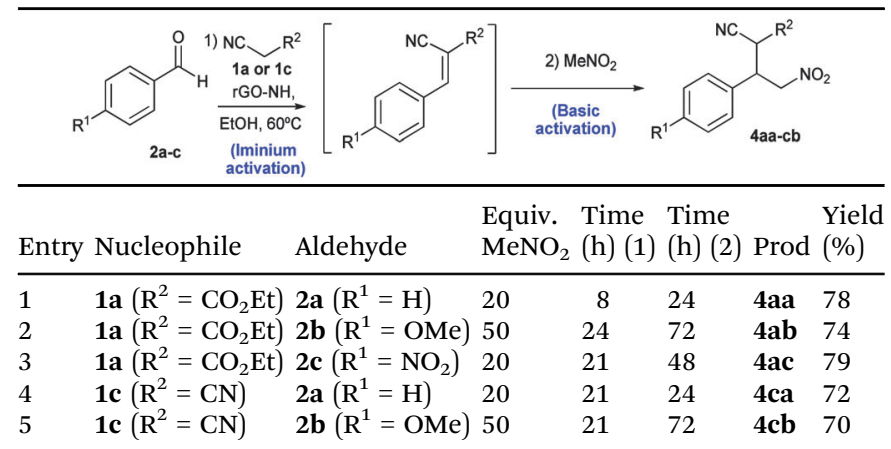

${ }^{a} 0.3 \mathrm{mmol}$ of aldehyde was used and $50 \mathrm{mg}$ of rGO-NH was used.

Knoevenagel-Michael sequence. We observed that rGO-NH catalysed the Michael addition via formation of 4 ac with a $71 \%$ yield after $8 \mathrm{~h}$ of reaction (Scheme 2).

Once the viability of both independent processes was established, we demonstrated, with some representative examples, that rGO-NH was capable of catalysing the one-pot Knoevenagel-Michael process. Using nucleophiles 1a and 1c and aldehydes $\mathbf{2 a - c}$ in the first step, and just adding nitromethane for the second step, the sequential procedure worked efficiently (Table 2 ).

After demonstrating the synthetic utility of the rGO-NH, we wanted to assess the role of the support on the reactivity of this new solid catalyst. If the initial hypothesis of the stabilization of positively charged intermediates due to the electronic properties ${ }^{5}$ of graphene were operative, we should observe a more significant effect of the support in reactions that imply iminium ion activation than in those that require enamine activation.

To evaluate this difference we systematically analysed the effect of the catalyst (rGO-NH) and all the separated components in the Michael addition of nitromethane to enals and the aldol reaction of acetone, which presumably occur via iminium ion and enamine activation, respectively (Tables 3 and 4). ${ }^{15}$ We have chosen the Michael addition of enals for this study because, if the iminium mechanism was not operating, the 1,2-addition products would be also obtained. ${ }^{16}$ A comparison of the efficiency of the reaction and the ratio of products obtained with different materials could give us a qualitative idea of the stabilizing role of the support.

We initially demonstrated that rGO-NH was able to catalyse the Michael reaction with both aromatic and aliphatic enals affording the 1,4 adduct as the main products (entries 1 and 2). We even used p-chlorocinnamaldehyde (2h) (Table 3, entry 3), because adduct $\mathbf{6 h}$ is an immediate precursor of Baclofen (see structure in Table 3), a drug used to treat, among other afflictions, muscle spasms caused by multiple sclerosis or spinal cord disease. ${ }^{17}$ 
Table 3 Michael addition of nitromethane to enals via iminium activation

\begin{tabular}{|c|c|c|c|c|c|c|c|}
\hline & il & 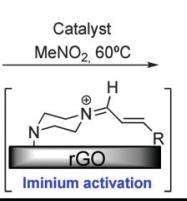 & $\int^{\mathrm{NO}_{2}}$ & & & $\int_{\mathrm{OH}}$ & \\
\hline \multicolumn{3}{|c|}{ Entry Aldehyde ${ }^{a}$} & Catalyst & $\begin{array}{l}\text { Time } \\
\text { (h) }\end{array}$ & $\begin{array}{l}\text { Conv. } \\
(\%)\end{array}$ & $\begin{array}{l}\text { Ratio } \\
\mathbf{5 / 6}\end{array}$ & $\begin{array}{l}\text { Yield } \\
6(\%)\end{array}$ \\
\hline 1 & \multicolumn{2}{|c|}{$2 \mathbf{d}(\mathrm{R}=\mathrm{Ph})$} & rGO-NH ${ }^{e}$ & 72 & 77 & $27 / 73$ & 45 \\
\hline 2 & \multirow{2}{*}{\multicolumn{2}{|c|}{$\begin{array}{l}2 \mathrm{e}(\mathrm{R}=\mathrm{Me}) \\
2 \mathrm{~h}\left(\mathrm{R}=p-\mathrm{Cl}-\mathrm{C}_{6} \mathrm{H}_{4}-\right)\end{array}$}} & rGO-NH ${ }^{e}$ & 72 & n.d. & $8 / 92$ & 58 \\
\hline 3 & & & rGO-NH ${ }^{e}$ & 48 & 55 & $21 / 79$ & $71^{f}$ \\
\hline 4 & \multicolumn{2}{|c|}{$2 \mathrm{e}(\mathrm{R}=\mathrm{Ph})$} & $\mathrm{rGO}^{b}$ & 72 & 0 & - & - \\
\hline 5 & \multicolumn{2}{|c|}{$2 \mathbf{e}(\mathrm{R}=\mathrm{Ph})$} & Piperazine $^{c}$ & 72 & 56 & $86 / 14$ & n.d. \\
\hline 6 & \multicolumn{2}{|c|}{$2 \mathrm{e}(\mathrm{R}=\mathrm{Ph})$} & rGO/piperazine ${ }^{d}$ & 72 & 60 & $56 / 44$ & 16 \\
\hline 7 & \multicolumn{2}{|c|}{$2 \mathrm{e}(\mathrm{R}=\mathrm{Ph})$} & GO-NH ${ }^{e}$ & 72 & $>95$ & $51 / 49$ & 37 \\
\hline
\end{tabular}

${ }^{a} 0.3 \mathrm{mmol}$ of aldehyde was used. ${ }^{b} 50 \mathrm{mg}$ of rGO was used. ${ }^{c} 5 \mathrm{~mol} \%$ was used. ${ }^{d} 50 \mathrm{mg}$ of rGO and $5 \mathrm{~mol} \%$ of piperazine were used. ${ }^{e} 50 \mathrm{mg}$ was used. ${ }^{f}$ Based on the recovered starting material.

Table 4 Aldol condensation

\begin{tabular}{|c|c|c|c|c|c|c|c|}
\hline & $\begin{array}{l}\text { Catalyst } \\
60^{\circ} \mathrm{C}, \mathrm{t}\end{array}$ & $7 a-c$ & \multicolumn{2}{|c|}{$8 a-c$} & \multicolumn{3}{|c|}{$\begin{array}{l}\mathrm{rGO} \\
\text { Enamine activation }\end{array}$} \\
\hline Entry & Aldehyde & Catalyst & $\begin{array}{l}\text { Time } \\
\text { (h) }\end{array}$ & $\begin{array}{l}\text { Conv. } \\
(\%)\end{array}$ & $\begin{array}{l}\text { Ratio } \\
7: 8\end{array}$ & $\begin{array}{l}\text { Yield } \\
7(\%)\end{array}$ & $\begin{array}{l}\text { Yield } \\
8(\%)\end{array}$ \\
\hline 1 & $2 \mathbf{a}(\mathrm{R}=\mathrm{H})$ & rGO-NH & 72 & $>90$ & $53: 47$ & 39 & 37 \\
\hline 2 & $2 \mathrm{c}\left(\mathrm{R}=\mathrm{NO}_{2}\right)$ & rGO-NH & 48 & 87 & $83: 17$ & $77^{a}$ & $15^{a}$ \\
\hline 3 & $2 \mathbf{b}(\mathrm{R}=\mathrm{OMe})$ & rGO-NH & 72 & 45 & $31: 69$ & $15^{a}$ & $47^{a}$ \\
\hline 4 & $2 \mathbf{b}(\mathrm{R}=\mathrm{OMe})$ & rGO & 72 & 0 & n.r. & - & - \\
\hline 5 & $2 \mathbf{b}(\mathrm{R}=\mathrm{OMe})$ & Piperazine & 72 & 49 & $6: 94$ & n.d. & $56^{a}$ \\
\hline 6 & $2 b(\mathrm{R}=\mathrm{OMe})$ & rGO + Pip & 72 & 37 & $4: 96$ & n.d. & $61^{a}$ \\
\hline
\end{tabular}

Using cinnamaldehyde (2e) as the enal we carried out several comparative experiments. ${ }^{12}$ We proved that the support rGO was unsuccessful as a catalyst (entry 4). In contrast, free piperazine afforded diene $\mathbf{5 e}$ (formed by dehydration of the 1,2 adduct) with moderate conversion but in a higher ratio than the 1,4 adduct $6 \mathrm{e}$. This ratio contrasts with the one obtained when using rGO-NH (compare entries 1 and 5), indicating an influence of the rGO support. Interestingly, when piperazine and rGO were introduced into the same reaction vessel, the ratio of the 1,4-adduct increased with respect to piperazine itself (compare entries 5 and 6). GO-NH, the precursor of rGO$\mathrm{NH}$, afforded a higher conversion but a lower ratio of the 1,4 adduct (entry 7). The higher ratio of the 1,4-products when using rGO as an additive and to a greater extent when it is directly anchored to the catalyst (rGO-NH), suggests a possible stabilization of the iminium ion intermediate due to the electronic density of the surface of the graphene derivative.

rGO-NH was also able to catalyze the aldol condensation of aromatic aldehydes (2a-c) using acetone as solvent and nucleophile to afford a mixture of aldols 7 and alkenes 8 (Table 4, entries $1-3$ ). In the case of aldehyde $\mathbf{2 b}$ we could demonstrate that, as suspected, the effect of the rGO as support was almost insignificant. rGO did not show any catalytic activity (entry 4), and piperazine afforded comparable results to rGO-NH in terms of yield; only a slightly different ratio of aldol $7 \mathbf{b}$ to enone $\mathbf{8 b}$ was observed (compare entries 3 and 5). The combination of rGO and piperazine as catalysts (entry 6) afforded similar results to piperazine. These results seem to indicate a null effect of the support in this reaction.

Piperazine has been successfully anchored to an rGO surface. The resulting heterogeneous bifunctional and recyclable catalyst has been characterized and effectively applied to a variety of organic transformations such as Knoevenagel, Michael and aldol reactions, which follow different activation pathways. The synthetic utility of the new catalyst has been demonstrated via the preparation of several intermediates of interest such as precursors of baclofen and TCNQ. The comparison of the catalytic activity of the new material rGO-NH with some precursors suggests an effect of the surface stabilizing positively charged intermediates. The search for new aminocatalytic systems, combining different amines and graphenetype supports to explore the effect of the electronic properties of the surface on their catalytic activity, is currently being conducted in our lab.

We thank the Spanish Government (CTQ-2012-35957) and CAM (AVANCAT CS2009/PPQ-1634) for financial support. E.R. thanks the Spanish Ministry for a predoctoral fellowship (FPU/AP-2010-0807). R.S. thanks the Spanish Ministry of Science for a postdoctoral contract (PTQ-11-04601). We thank Manuel López Granados and Rafael Mariscal for useful discussions about FT-IR interpretation and $\mathbf{M}^{\mathrm{a}}$ José de la Mata for her help with thermogravimetric analyses.

\section{Notes and references}

1 (a) X. Huang, X. Qi, F. Boey and H. Zhang, Chem. Soc. Rev., 2012, 41, 666; (b) V. Georgakilas, M. Otyepka, A. B. Bourlinos, V. Chandra, N. Kim, K. C. Kemp, P. Hobza, R. Zboril and K. S. Kim, Chem. Rev., 2012, 112, 6156.

2 (a) D. R. Dreyer and C. W. Bielawski, Chem. Sci., 2011, 2, 1233; (b) C. Su and K. P. Loh, Acc. Chem. Res., 2013, 46, 2275, and references cited herein; (c) A. Dhakshinamoorthy, M. Alvaro, P. Concepción, V. Fornés and H. Garcia, Chem. Commun., 2012, 48, 5443; (d) A. Dhakshinamoorthy, M. Alvaro, M. Puche, V. Fornés and H. Garcia, ChemCatChem, 2012, 4, 2026; (e) A. D. Todd and C. Bielawski, Catal. Sci. Technol., 2013, 3, 135. Example of not covalently modified catalyst derived from graphene: $(f) \mathrm{T}$. Wu, X. Wang, H. Qiu, J. Gao, W. Wang and Y. Liu, J. Mater. Chem., 2012, 22, 4772 .

3 (a) C. Yuan, W. Chen and L. Yan, J. Mater. Chem., 2012, 22, 7456; (b) W. Zhang, S. Wang, J. Ji, Y. Li, G. Zhang, F. Zhang and X. Fan, Nanoscale, 2013, 5, 6030; (c) Y. Li, Q. Zhao, J. Ji, G. Zhang, F. Zhang and X. Fan, RSC Adv., 2013, 3, 13655; (d) F. Zhang, H. Jiang, X. Li, X. Wu and H. Li, ACS Catal., 2014, 4, 394.

4 (a) S. V. Ley, I. R. Baxendale, R. N. Bream, P. S. Jackson, A. G. Leach, D. A. Longbottom, M. Nesi, J. S. Scott, R. I. Storer and S. J. Taylor, J. Chem. Soc., Perkin Trans. 1, 2000, 3815; (b) D. E. Bergbreiter, J. H. Tian and C. Hongfa, Chem. Rev., 2009, 109, 530.

5 Y. Pan, S. Wang, C. W. Kee, E. Duibson, Y. Yang, K. P. Loh and C. H. Tan, Green Chem., 2011, 13, 3341.

6 (a) H. B. Heersche, P. Jarillo-Herrero, J. B. Oostinga, L. M. K. Vandersypen and A. F. Morpurgo, Nature, 2007, 446, 56; (b) G. M. Rutter, J. N. Crain, N. P. Guisinger, T. Li, P. N. First and J. A. Stroscio, Science, 2007, 317, 219; (c) C. Gómez-Navarro, R. T. Weitz, A. M. Bittner, M. Scolari, A. Mews, M. Burghard and K. Kern, Nano Lett., 2007, 7, 3499.

7 C. K. Ingold, Structure and Mechanism in Organic Chemistry, Cornell University Press, Ithaca N.Y., 1953, p. 685. 
8 (a) D. W. C. MacMillan, Nature, 2008, 455, 304; (b) M. J. Gaunt, C. C. C. Johansson, A. McNally and N. T. Vo, Drug Discovery Today, 2007, 12, 8; (c) Science of Synthesis, Asymmetric Organocatalysis, ed. B. List and K. Maruoka, Thieme Chemistry, Germany, 2012, vol. 2, p. 1928.

9 W. S. Hummers and R. E. Offeman, J. Am. Chem. Soc., 1958, 80, 1339.

10 For other reactions of nucleophilic addition of secondary amines to graphene oxide (GO) see: A. B. Bourlinos, D. Gournis, D. Petridis, T. Szabó, A. Szeri and I. Dékány, Langmuir, 2003, 15, 6051.

11 D. Li, M. B. Müller, S. Gilje, R. B. Kaner and G. G. Wallace, Nat. Nanotechnol., 2008, 3, 101.

12 For more information see ESI $\dagger$.

13 (a) D. S. Acker and W. R. Hertler, J. Am. Chem. Soc., 1962, 84, 3370; (b) R. J. Crawford, J. Org. Chem., 1983, 48, 1366.
14 (a) J. Ferraris, D. O. Cowan, V. Walatka and J. H. Perlstein, J. Am. Chem. Soc., 1973, 95, 948; (b) J. R. Kirtley and J. Mannhart, Nat. Mater., 2008, 7, 520; (c) R. Gal-Oz, N. Patil, R. Khalfin, Y. Cohen and E. Zussman, ACS Appl. Mater. Interfaces, 2013, 5, 6066.

15 We have also compared the results obtained with rGO-NH in both Knoevenagel and Michael reactions with the precursor amines and materials. In the case of the Knoevenagel, it is difficult to determine the role of the support as different mechanisms would afford the same product see ESI $\dagger$.

16 (a) P. Diner, M. Nielsen, M. Marigo and K. A. Jørgensen, Angew. Chem., Int. Ed., 2007, 46, 1983; (b) R. Appel, S. Chelli, T. Tokuyasu, K. Troshin and H. Mayr, J. Am. Chem. Soc., 2013, 135, 6579.

17 L. Zu, H. Xie, H. Li, J. Wand and W. Wang, Adv. Synth. Catal., 2007, 349, 2660. 